\section{$\underset{\substack{\text { hommes } \\ \text { \& migrations }}}{ }$}

\section{Hommes \& migrations}

Revue française de référence sur les dynamiques

migratoires

$1320 \mid 2018$

Au prisme de la consommation

\title{
Tassadit Imache, Des cœurs lents
}

Marseille, Agone 2017, 183 p., $16 €$.

\section{Mustapha Harzoune}

\section{Q OpenEdition \\ 1 Journals}

\section{Édition électronique}

URL : http://journals.openedition.org/hommesmigrations/4096

DOI : 10.4000/hommesmigrations.4096

ISSN : 2262-3353

\section{Éditeur}

Musée national de l'histoire de l'immigration

\section{Édition imprimée}

Date de publication : 1 janvier 2018

Pagination : 168-169

ISBN : 978-2-919040-40-7

ISSN : 1142-852X

Référence électronique

Mustapha Harzoune, "Tassadit Imache, Des cœurs lents », Hommes \& migrations [En ligne], 1320 |

2018, mis en ligne le 01 janvier 2018, consulté le 06 janvier 2021. URL : http://

journals.openedition.org/hommesmigrations/4096; DOI : https://doi.org/10.4000/

hommesmigrations.4096 


\section{LIVRES}

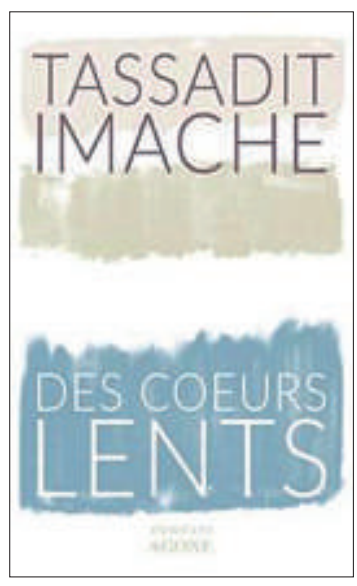

\section{Tassadit Imache} Des cœurs lents

Marseille, Agone 2017, 183 p., $16 €$.

Dans Des cours lents, roman d'une étonnante densité, tout en variations et mouvement, le propos comme les personnages balancent, sur le fil du rasoir. Fragiles. Créatifs ou vaincus. L'auteure fraye dans les interstices, là où les âmes blessées et les corps piégés se raidissent, s'enragent, se révoltent. Ou cèdent.

François transporte une cage lourde de perruches. Il est avec Bianca, sa sœur. Ils se retrouvent dans "cette ville de riches pour les riches ", où Tahir, le cadet, est venu s'enterrer; et mourir. La mort réveille le passé, avec d'autant plus de violence qu'on s'est efforcé de l'enfouir et de le fuir : "Tout ce temps, ils n'avaient été qu'en liberté surveillée".

Quinze ans plus tôt, Marceline - alias Iris - a abandonné ses enfants. Besoin de prendre l'air. D'aimer. Plane, ici, l'ombre de la faute. François et Bianca se chargent de Tahir. L'un renonce aux Beaux-Arts, l'autre poursuit des études supérieures. Sacrifice libérateur pour lui, succès empreint de culpabilité pour elle. Regrets et ressentiment n'aident pas à soigner les blessures. Tahir, lui, s'enfonce dans la dépression et la drogue. Faisait-il seulement partie de la famille, "le préféré de maman ", ce môme à la gueule et au prénom de bicot?

Il faut remonter le temps, revenir au Jardin des Plantes, là où deux solitudes se sont croisées, celle d'une jeune bretonne débarquée dans la capitale et d'un immigré kabyle à la " casquette de prolo français ". "C'était pendant la dernière guerre coloniale ", une guerre "sans le sourire de Gandhi. À la balle, au couteau, puis au napalm". À l'origine de cette famille française, il y a Marie et Mohammed, " une soif de justice et une soif d'amour entrecroisées par hasard. voyez-vous, le bicot ne savait rien de la justice. Marie ne savait rien de l'amour". Histoire d'une rencontre. Histoire d'un gâchis fait de manques et de silences. D'absences et de vides. De prisons et de délivrances. Le grand-père va crever " seul à l'hôpital avec son nom. C'est qu'on ne les aimait pas beaucoup dans nos hôpitauxàcetteépoque, les Maghrébins ". Plus tard, le père des gamins, Marco Jean, né sous $X$, se tuera dans un accident de moto, laissant Marceline avec trois orphelins. Les pères ne vivent pas longtemps. Répétitions généalogiques sur trois générations. Soif de justice et d'amour font les cœurs durs, lents, et les langues lourdes, "fermés mais fiers ». On hérite de mère en fille d'une colère dont on ignore l'origine et « de branche cassée en branche cassée, de trou en trou, on vous y pousse dedans... la dépression ".

Marceline viendra-t-elle à l'enterrement? La lumière se déplace. On découvre une femme rongée, révoltée, hantée par une question jamais posée à sa mère, "et si c'était à refaire?". Pourtant, par fidélité, elle a appelé son dernier Tahir! "Si j'avais su la suite, je l'aurais appelé Toni ", dit Marceline, alias Iris ou Fatma, qui recommande d'aller voir Élise ou la vraie vie: "C'est une preuve. Comme le radeau de la Méduse au Louvre ou la chaloupe du Titanic à New York. » Mais elle voudrait que « L'HISTOIRE de nous s'abstienne »-pour reprendre le 
poète Mourad Djebel. La mort de Tahir réveille les peurs de Marceline. " C,a $a$ recommencé. Elle est de nouveau dans l'Histoire. "Vivre libre n'est pas aisé à l'heure où « certains rêvaient de vous ausculter les gênes" pour soupeser votre loyauté ou vous museler, en vous coffrant dans une fausse appartenance. Au pays de Descartes, plus le droit de penser! Marceline, Iris ou Fatma ; Bianca, François ou Tahir... quelle importance. II s'agit de vivre libre. D'ouvrir la cage. De desserrer ces nœuds de la société et de l'histoire

\section{Victor Schœlcher tournaldevoyage en Égypte (1844)}

Paris, Mercure de France, 2017,442 p., $8,90 €$.

Dans le cadre d'un voyage d'étude sur tesclavage quile mena de 1840 à 1847 du Mexique au Sénégaten passant par les Antilles, Victor scholcher séjourna en Égypteen 1844. II en rapporta de nombreuses et précises informations sur l'esclavage biensûr, sur Y'antériorité et la prégnance de ta civilisation éthiopienne mais aussi sur la vie politique, culturelle, sur l'istam comme surte sort des plus humbles. qui étranglent, laissent sans voix, invisible. Le cœur lent. Expressive, émouvante (lire les épisodes de l'abandon, de l'enterrement ou la magnifique lettre de Marceline à Bianca), la phrase, sobre, se nourrit de blancs et de signes. Comme les cœurs lents. Rien de désespéré - « ily a encore tant à découvrir. Il y a des personnes chères, en vie "-dans ce bijou d'horlogerie dont les tic-tac et les silences rythment les existences. Et leur devenir. II faut juste (ré)apprendre à placer la lumière.

M. H.

Ge qui peut surprendre le lecteur contemporain, c'est l'exigence intellectuette, te souci pédagogique, la hauteur de vue de l'auteur qui s'appuie sur une solide documentation, nourrie de rencontres et d'observations de terrain. tacuité du regard de Schoetcher, te souci des questions sociates restent une source d'inspiration. Lire ce journat, e'est encore aujourd'hui - surtout aujourd'hui-sedétourner des diabolisations et globalisations à tout va, remettre dudiscernementet de la profondeur historique, rappeter qu'il existe des divergences d'intérêts socio-économiques (ta fameuse lutte de classes) et qu'une bonne politique extérieure exige, sice n'est de voir loin, à tout te moins de res= pectersesvateursenne se trompant pas de partenaire: 